Journal of Applied Pharmaceutical Science Vol. 6 (06), pp. 113-118, June, 2016

Available online at http://www.japsonline.com

DOI: $10.7324 /$ JAPS.2016.60620

ISSN 2231-3354 (cc) EY-NC-SA

\title{
Attenuation of Neuronal Damage by Gymnemic acid in Experimentally Induced Cerebral Ischemia in Rats
}

\author{
Kiran P. Narkhede, Anandrao R. Kulkarni ${ }^{*}$, Chetan Savant \\ Faculty of Pharmacy, PRIST University, Thanjavur, India., Soniya Education Trust's College of Pharmacy, Dharwad, 580 002, India.
}

\begin{tabular}{lll}
\hline ARTICLE INFO & ABSTRACT \\
\cline { 3 - 3 } $\begin{array}{l}\text { Article history: } \\
\text { Received on: } 02 / 03 / 2016\end{array}$ & $\begin{array}{l}\text { Gymnemic acid is obtained from the natural resource and has got antioxidant property, was investigated for the } \\
\text { pessible neuroprotective effect in experimentally induced cerebral ischemic rats. Carotid arteries clamped with } \\
\text { the help of aneurysm clips to produce cerebral ischemia, the clips were removed from the arteries to allow the } \\
\text { Accepted on: } 21 / 05 / 2016\end{array}$ \\
$\begin{array}{ll}\text { Available online: } 28 / 06 / 2016 \\
\text { reflow of the blood through carotid arteries. It was observed that lipid peroxidation was increased significantly } \\
\text { after bilateral common carotid artery occlusion. Brain endogenous antioxidant GSH and total protein levels were } \\
\text { low. Administration of gymnemic acid in a dose of } 250 \mathrm{mg} / \mathrm{kg} \text { and } 500 \mathrm{mg} / \mathrm{kg} \text { b.w orally showed promising } \\
\begin{array}{l}\text { Gymnemic acid, BCCAO, } \\
\text { neuroprotective, oxidative } \\
\text { stress, acetyl cholinesterase. }\end{array}\end{array} \quad \begin{array}{l}\text { neuroprotective effect by reducing cerebral infarct size as well as improved all antioxidant levels showing } \\
\text { activity against oxidative stress. }\end{array}$ \\
\hline
\end{tabular}

\section{INTRODUCTION}

Gymnemic acid is a Phytoconstituent used as a food supplement in patients suffering from various diseases and disorders. It is extracted from the leaves of plant Gymnema sylvestre belonging to family Asclepiadaceae. Literature in the traditional methods of medicines mentioned about the gymnemic acid regarding its potent antidiabetic activity especially in folk, ayurvedic and homeopathic systems of medicine, also used in the treatment of asthma, eye complaints, inflammations, family planning and snakebite (Kamalavali et al., 2000). Chemically gymnemic acids are derivatives of triterpene saponins of oleanane class with at least nine closely related acidic glucosides (Dateo et al., 1973; Manni et al., 1965; Maeda et al., 1989; Sinsheimer et al., 1971). Gymnemic acid along with antidiabetic activity it also possesses various activities like antihyperlipidemic, antiviral, antimicrobial, antibacterial and

\footnotetext{
* Corresponding Author

Anandrao R. Kulkarni, Soniya Education Trust's College of Pharmacy,

Dharwad, 580 002, India. Email: kulkarni73@yahoo.com
}

hepatoprotective (Shigematsu et al., 2011; Porchezhian et al., 2013; Satdive et al., 2003; Tominaga et al ., 1995; Yogisha et al., 2009; Bhatiya et al., 2008). Recently it is mentioned use of gymnemic acid formulations in patients with overweight. (Yoshikawa et al., 1993). Due to its enormous health benefits, gymnemic acid formulations are being sold in the form of Gymnema Tea (Nakamura et al., 1999). Antioxidants were investigated for various neuronal disorders as the one of the major path neural damage is by oxidative stress and approximately 1.4 million people sustain traumatic brain injury (TBI) in the United States every year due to oxidative stress. There is compelling clinical need for real-time serum biochemical marker tests to aid in the diagnosis and severity stratification of head injuries (Wei ming lin et al., 2014). Stroke is the world's second leading cause of mortality occurs due to cerebral ischemia and resulting in around 6,000,000 deaths annually (WHO 2014; Seshadri et al., 2006). However, antioxidants and regular administration of food supplements containing antioxidants have health benefits in patients with stoke like diseases. Advancement in the technology, change in life style and food habits of human beings are suffering from excessive stress. 
In addition to stress regularly exposed to a variety of oxidizing agents due to pollution in air, food, and water, or they may be produced by metabolic activities within biological system. There is an always well balance in the biological system between oxidants and antioxidants to sustain optimal physiologic conditions. Imbalance in between oxidants and antioxidants in body leading to oxidative stress and related disorders which can be prevented by administration of sufficient amounts of antioxidant such as phenolics and carotenoids that may help protect cellular systems from oxidative damage and lower the risk of chronic diseases. Hence, the present work was undertaken to evaluate possible neuroprotective effects of gymnemic acid in experimentally induced cerebral ischemic rats.

\section{MATERIALS AND METHODS}

\section{Chemicals}

Gymnemic acid was obtained from Natural Remedies, Bangalore, India. DTNB, TBA, methanol, bovine serum albumin, sodium tartrat, tween 80, n-hexane, TCA, Ellman's reagent (5,5'dithiobis (2-nitrobenzoic acid), and other chemicals were obtained from Himedia Laboratories, Mumbai, India.

\section{Animals}

Rats of either sex were purchased from Sri Venkateshwara Enterprises; Bangalore, India weighing in between 180-200 g were used for the study. They were maintained in the animal house of S.E.T's College of Pharmacy, Dharwad, India for experimental purpose. The animals were maintained under controlled conditions of temperature $\left(23 \pm 2^{\circ} \mathrm{C}\right)$, humidity $(50 \pm$ $5 \%)$ and 12-h light-dark cycles. They were having free access to standard pellets as basal diet and water ad libitum. The animals were housed individually in sanitized polypropylene cages containing sterile paddy husk as bedding. Animals were habituated to laboratory conditions for $48 \mathrm{~h}$ prior to experimental protocol to minimize if any of non-specific stress. All the studies conducted were approved by the Institutional Animal Ethical Committee (IAEC) of SET's College of Pharmacy, Dharwad, India (REG.No.112/1999/CPCSEA) according to prescribed guidelines of Committee for the Purpose of Control and Supervision of Experiments on Animals (CPCSEA), Government of India.

\section{Induction of cerebral ischemia by bilateral common carotid artery occlusion (BCCAO)}

Cerebral ischemia was produced in rats by bilateral common carotid artery occlusion. Animals were administered with pentobarbitone $(50 \mathrm{mg} / \mathrm{kg} \mathrm{BW})$ for induction of anesthesia. Both the right and left common carotid arteries were isolated by making incision and made free from surrounding tissues and vagus nerve separated. Cerebral ischemia was induced by clamping both the arteries with the help of aneurysm clips. After $10 \mathrm{~min}$ of cerebral ischemia; the clips were removed from the arteries to allow the reflow of the blood through carotid arteries. The incision was sutured back in layers with surgical suture. While performing the surgical procedure; the body temperature was maintained at $37^{\circ} \mathrm{C}$ by heated IR lamp. All surgical instruments used in procedure were sterilized prior to use (Masaya et al., 1999).

\section{Experimental Design}

Five groups of six rats were made. The first group I was normal control treated with only vehicle (Distilled water 1 $\mathrm{ml} / \mathrm{p}$.o.). In the second group II which was treated as Sham only surgery was performed but no cerebral ischemia was induced. Group III was cerebral ischemia group, in this group all the animals were operated to induce cerebral ischemia as per procedure mentioned in the previous section and treated with vehicle (Distilled water $1 \mathrm{ml} / \mathrm{p}$. o.). Group IV was gymnemic acid treated group, in this group gymnemic acid was administered (250 $\mathrm{mg} / \mathrm{kg}$,b.w) $30 \mathrm{~min}$ before cerebral ischemia and 24 hours after $1^{\text {st }}$ dose. Group V was gymnemic acid treated group, in this group gymnemic acid was administered $(500 \mathrm{mg} / \mathrm{kg}$, b.w) $30 \mathrm{~min}$ before cerebral ischemia and $24 \mathrm{~h}$ after $1^{\text {st }}$ dose.

\section{Preparation of post-mitochondrial supernatant}

Whole brain was removed by cutting the skull bone and tissue was washed in cooled $0.9 \%$ saline, kept on ice and subsequently blotted on filter paper, then weighed and homogenized as $10 \%(\mathrm{w} / \mathrm{v})$ in cold phosphate buffer $(0.05 \mathrm{M}$, pH 7.4). The homogenates were centrifuged at $1000 \times \mathrm{g}$ for $10 \mathrm{~min}$ at $4^{\circ} \mathrm{C}$ and post-mitochondrial supernatant (PMS) was kept on ice until assayed (Kiran et al., 2015).

\section{Biochemical Estimation \\ Estimation of Total Protein}

The estimation of total protein content was done using kit of Erba as per Biuret Methods, End point method. $1 \mathrm{ml}$ of this working reagent was pipette out in each of the test tubes labeled as blank, standard, test. $20 \mu \mathrm{l}$ of distilled water, $20 \mu \mathrm{l}$ of standard and $20 \mu \mathrm{l}$ of sample homogenate was pipette out and added to test tubes labeled as blank, standard, and test respectively. Test tubes were incubated for $10 \mathrm{~min}$ at $37^{\circ} \mathrm{C}$. Reading was obtained by measuring the absorbance at $546 \mathrm{~nm}(520-560 \mathrm{~nm})$ in the autoanalyser of standard and each test against reagent blank (Kiran $e t$ al., 2015).

Total Protein $(\mathrm{g} / \mathrm{dl})=($ Absorbance of test/Absorbance of standard $)$ $\mathrm{X}$ Concentration of standard $(\mathrm{g} / \mathrm{dl})$.

\section{Estimation of brain lipid peroxidation assay (TBARS) level}

Lipid peroxidation in tissues was estimated colorimetrically by thiobarbituric acid reactive substances and hydroperoxides according to the methods of Nichans and Samuelson 111 and Jiang et al., respectively. In brief, $0.1 \mathrm{ml}$ of tissue homogenate (supernatant; Tris-HCL buffer, $\mathrm{pH}$ 7.5) was treated with $2 \mathrm{ml}$ of (1:1:1 ratio) TBA-TCA-HCL reagent $(0.37 \%$ thiobarbituric acid, $0.25 \mathrm{~N} \mathrm{HCl}$, and 15\% TCA), placed in water bath for $15 \mathrm{~min}$, cooled, and centrifuged at room temperature for $10 \mathrm{~min}$. The absorbance of clear supernatant was measured against 
reference blank at $535 \mathrm{~nm}$ and expressed as micro moles per gram of tissue (Dalla et al., 2009).

\section{Estimation of brain GSH level}

GSH was determined by the method of Ellman. A known weight of tissue was homogenized in phosphate buffer. From this $0.5 \mathrm{ml}$ was pipette out and precipitated with $2 \mathrm{ml}$ of $5 \%$ TCA. $1 \mathrm{ml}$ of the supernatant was taken after centrifugation at $3200 \mathrm{~g}$ for 20 min and added to it $0.5 \mathrm{ml}$ of Ellman's reagent and $3 \mathrm{ml}$ of phosphate buffer ( $\mathrm{pH} 8.0)$. Then the absorbance was read at 412 $\mathrm{nm}$. A series of standards were treated in a similar manner along with a blank containing $3.5 \mathrm{ml}$ of buffer. The values were expressed as micro moles per gram of tissue (Dalla et al., 2009).

\section{Estimation of acetyl cholinesterase enzyme activity of whole brain}

The brain was homogenized in a tissue homogenizer. 400 mg of brain was homogenized in $0.1 \mathrm{M}$ Phosphate buffer $\mathrm{pH} 8$ $(10 \% \mathrm{w} / \mathrm{v})$, the homogenized tissue was centrifuged to $10,000 \mathrm{rpm}$ for $10 \mathrm{~min}$. $0.4 \mathrm{ml}$ aliquot of the supernatant is added to a cuvette containing $2.6 \mathrm{ml}$ phosphate buffer $(0.1 \mathrm{M}, \mathrm{pH} 8)$ and $100 \mu \mathrm{l}$ of DTNB. The contents of the cuvette were mixed thoroughly by bubbling air and absorbance is measured at $412 \mathrm{~nm}$. When absorbance reaches a stable value, it is recorded as the basal reading. $20 \mu \mathrm{l}$ of substrate i.e., acetylthiocholine is added and change in absorbance is recorded for a period of $10 \mathrm{~min}$ at intervals of $2 \mathrm{~min}$. Change in the absorbance per minute is thus determined. AchE activity is calculated using the formula (Kiran et al., 2015).

$$
\mathrm{R}=5.74 \times 10-4 \times \mathrm{A} / \mathrm{CO}
$$

Where,

$\mathrm{R}=$ Rate in moles of substrate hydrolyzed /minute /gm of brain tissue

$\mathrm{A}=$ Change in absorbance $/ \mathrm{min}$.

$\mathrm{CO}=$ Original concentration of the tissue $(\mathrm{mg} / \mathrm{ml})$

\section{Histopathology}

Rats were deeply anaesthetized with pentobarbitone and the brains were taken out and fixed in $10 \%$ formalin. Multiple, paraffin-embedded, coronal sections (5-Am thick) were taken from each brain (spanning through striatum to caudal hippocampus). Serial sections (spaced apart by $250 \mathrm{Am}, 15$ in total for each brain) were selected for histopathological analysis of neuronal damage. After staining with hematoxylin and eosin, the slides were examined using light microscopy by an observer blinded to experimental groups. The brain was subjected to histopathology and observed for infarct cells. The samples were submitted to Jeevan Lab Pvt Ltd. (Belgaum, India) for histopathological examination (Oisson et al., 2003).

\section{Measurement of infarction area:}

The infarction area was measured by 2, 3, 5-triphenyl terazolium chloride (TTC) staining method. After ischemia and reperfusion animals were sacrificed, and brains were removed within 2-3 min. Two coronal slices were made at 5 and $7 \mathrm{~mm}$ from the frontal pole, and brain slices were immersed in $2 \%$ solution of TTC stain in normal saline at $37^{\circ} \mathrm{C}$ for $30 \mathrm{~min}$. After which sections were fixed in $10 \%$ phosphate buffered formalin for photograph. Then the cerebral infarction area was observed and compared between various treatment group and negative control group (Kiran et al., 2015).

\section{Statistical analysis}

The data obtained by the various parameters was statistically evaluated by one way Analysis of variance (ANOVA) followed by Tukey's post-test using Graph Pad Prism software. The mean values \pm SEM were calculated for each parameter.

\section{RESULTS}

\section{Total protein activity (g/dL)}

Samples containing proteins react with copper II ions in alkaline solution to form blue-violet complex as per biuret reaction and each copper ion complexion with 5 or 6 peptide bonds. However, the colour formed is stabilized by the addition of Tartarate to prevent auto-reduction of the alkaline copper complex. The colour formed is proportional to the protein concentration and is measured at $546 \mathrm{~nm}(520-560 \mathrm{~nm})$. The total protein activity showed significant decrease $(\mathrm{P}<0.001)$ in total protein level of positive control group (Cerebral ischemia induced group) compared to vehicle control group and sham control group. Gymnemic acid treated groups $250 \mathrm{mg} / \mathrm{kg}$ and $500 \mathrm{mg} / \mathrm{kg}$ p.o. showed significant $(\mathrm{P}<0.01)$ and $(\mathrm{P}<0.001)$ increase in total protein level compared to positive control group (Cerebral ischemia induced group) respectively (see Figure 1). Results are summarized in Table1.

\section{TOTAL PROTEIN}

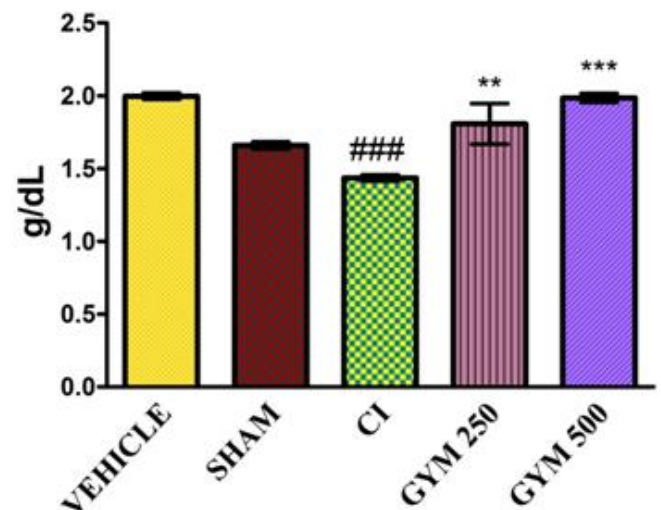

Fig. 1: Effect of Gymnemic acid (250 and $500 \mathrm{mg} / \mathrm{kg}$ ) on Total Protein activity in BCCAO induced global cerebral ischemia.

\section{Lipid Peroxidase (LPO) activity ( $\mu \mathrm{mol} / \mathrm{g})$}

Peroxidation of cellular lipids results into oxidative stress and which is determined by measurement of thiobarbituric acid reacting substance (TBARS). The concentration of LPO products may reflect the degree of oxidative stress. The increased level of TBARS results in increased of oxidative free radicals, which 
attacks the polyunsaturated fatty acids in cell membranes and cause lipid peroxidation. The malondialdehyde (MDA) content, a measure of lipid peroxidation was assayed in the form of TBARS. The Lipid peroxides (LPO) assay showed significant $(\mathrm{P}<0.001)$ increase in LPO activity of positive control group (Cerebral ischemia induced group) compared to vehicle control group and sham group. Gymnemic acid treated $250 \mathrm{mg} / \mathrm{kg}$ and $500 \mathrm{mg} / \mathrm{kg}$ p.o. groups showed significant $(\mathrm{P}<0.05)$ and $(\mathrm{P}<0.001)$ reduction in LPO activity compared to the positive control group respectively (see Figure 2). Results are summarized in Table 1.

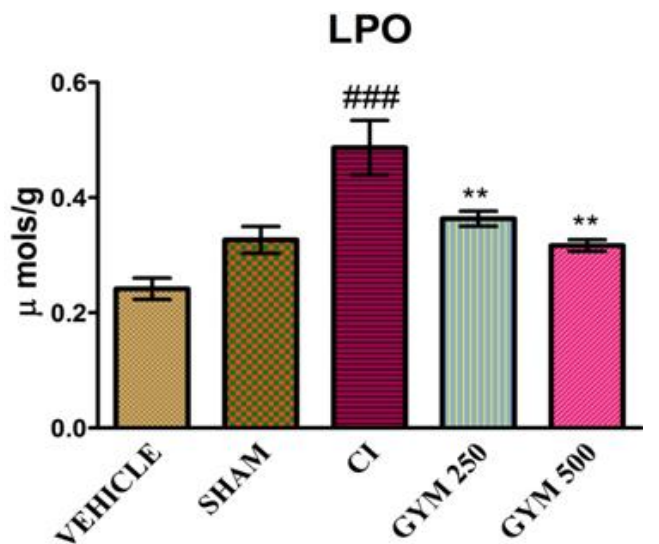

Fig. 2: Effect of Gymnemic acid (250 and $500 \mathrm{mg} / \mathrm{kg}$ ) on Lipid Peroxidase (LPO) activity in BCCAO induced global cerebral ischemia.

\section{Reduced Glutathione (GSH) activity $(\mu \mathrm{mol} / \mathrm{g})$}

GSH is a major non-protein thiol and endogenous antioxidant that counters balance free radical mediated damage. It is involved in the protection of normal cell structure and function by maintaining the redox homeostasis, quenching of free radicals and by participating in detoxification reaction. The reduced glutathione assay showed significant decrease $(\mathrm{P}<0.001)$ in $\mathrm{GSH}$ level of positive control group (Cerebral ischemia induced group) compared to vehicle control group and sham control group. Gymnemic acid treated $250 \mathrm{mg} / \mathrm{kg}$ and $500 \mathrm{mg} / \mathrm{kg}$ p.o. groups showed significant $(\mathrm{P}<0.001)$ increase in GSH level compared to positive control group (Cerebral ischemia induced group) (see Figure 3). Results are summarized in Table 1.

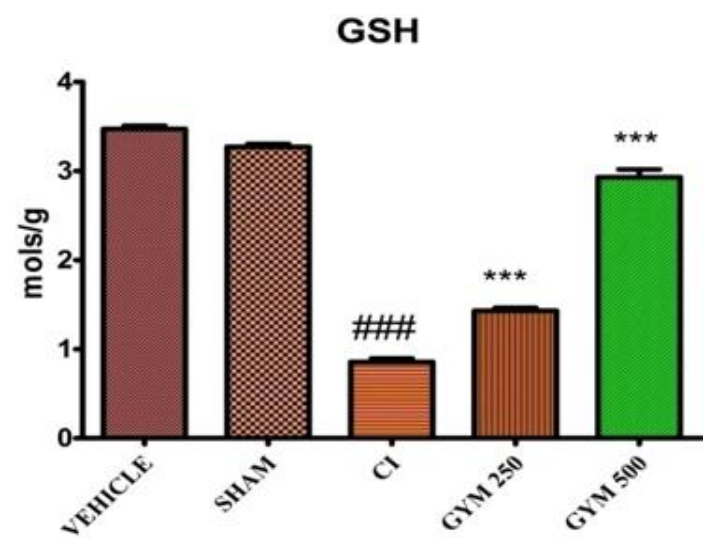

Fig. 3: Effect of Gymnemic acid (250 and $500 \mathrm{mg} / \mathrm{kg}$ ) on Reduced Glutathione (GSH) activity in BCCAO induced global cerebral ischemia.

\section{Acetyl cholinesterase (AChE) activity ( $\mu \mathrm{mols} / \mathrm{min} / \mathrm{mg})$}

The Acetyl cholinesterase assay showed significant increase in AChE level of positive control group (Cerebral ischemia induced group) compared to vehicle control group and sham control group. Gymnemic acid treated group $(500 \mathrm{mg} / \mathrm{kg}$ p.o.) showed significant $(\mathrm{P}<0.01)$ decrease in $\mathrm{AChE}$ level compared to positive control group (Cerebral ischemia induced group) (see Figure 4). Results are summarized in Table 1.

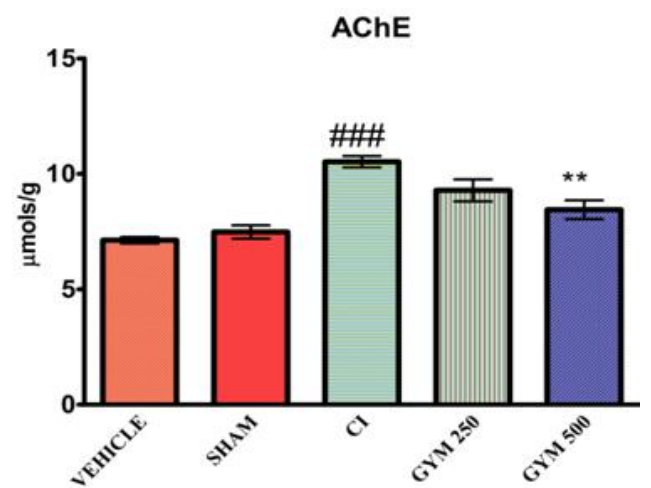

Fig. 4: Effect of Gymnemic acid ( 250 and $500 \mathrm{mg} / \mathrm{kg}$ ) on Acetyl cholinesterase (AChE) activity in BCCAO induced global cerebral ischemia.

\section{Effect of Gymnemic acid on cerebral infarction}

Bilateral carotid artery occlusion causes cerebral ischemia in rats resulted in cerebral tissue damage resulting in large infarction area, as indicated by lesser TTC staining when compared to control. Ischemia followed by reperfusion lead to further increase in infarction area, as indicated by further less TTC staining when compared to control. Pretreatment with Gymnemic acid prevented tissue damage and hence infarction induced by ischemia and reperfusion as shown by increase in TTC staining, when compared to cerebral ischemia group. Hence, pretreatment with Gymnemic acid showed marked reduction infarction area near to normal as indicated by further increase in TTC staining when compared to cerebral ischemia group.

\section{Histopathological Study}

Results of histopathological study of brain from positive control and pretreated with gymnemic acid were displayed in Figure 5. Positive control group was undergone surgery using bilateral common carotid artery occlusion to induce cerebral ischemia. It was observed that hippocampal and striatum parts of brain significantly change due to ischemia which was also confirmed by staining with hematoxylin and eosin; these were shown in Figure. The brain sections of bilateral carotid artery occlusion induced cerebral ischemia in rats showed marked cerebral edema, moderate cerebral congestion, and mild neutrophilic Infiltration. Ischemia followed by reperfusion resulted in moderate cerebral edema, marked cerebral congestion, moderate neuronal vacuolization and mild neutrophilic infiltration. Pretreatment with Gymnemic acid reduced these alterations as indicated by mild cerebral edema, cerebral congestion and mild neutrophilic infiltration. 

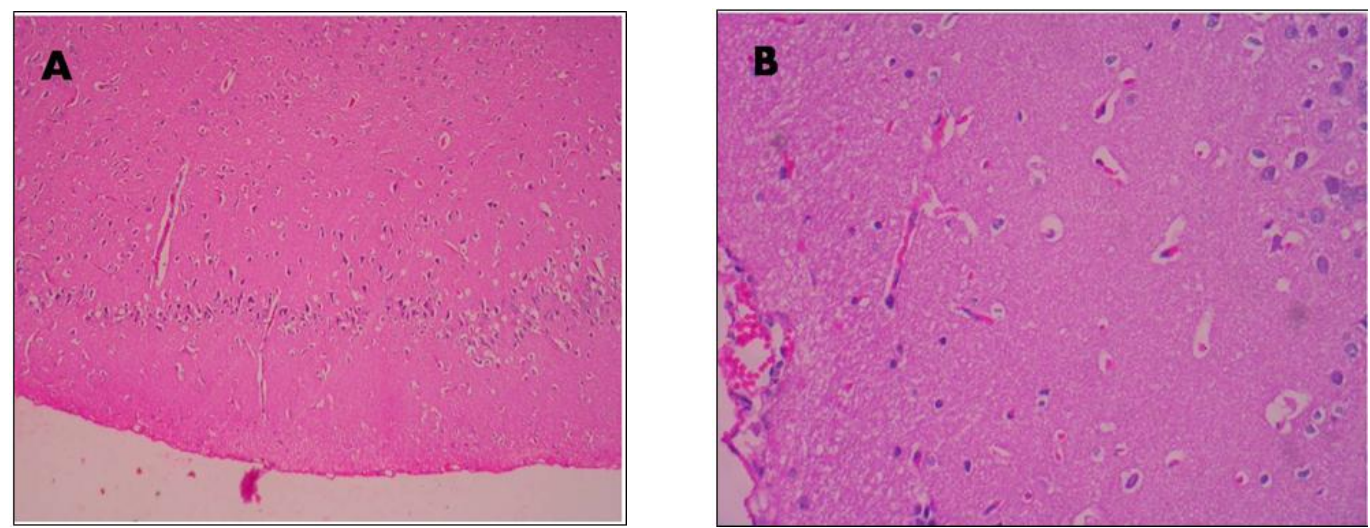

Fig. 5: Histopathological Study. (A): A typical brain section of brain sections of bilateral carotid artery occlusion induced cerebral ischemia in treated rats group showing marked improvements. (B): Brain section of bilateral carotid artery occlusion induced cerebral ischemia in rats showing marked cerebral edema, moderate cerebral congestion, and mild neutrophilic Infiltration.

Table 1: Results of total protein, lipid peroxidise (LPO), reduced glutathione (GSH) and acetyl cholinesterase (AChE) activities of various groups.

\begin{tabular}{llcccc}
\hline S. No. & Groups & Total Protein $(\mathbf{g} / \mathbf{d L})$ & LPO $(\boldsymbol{\mu m o l s} / \mathbf{g})$ & GSH $(\boldsymbol{\mu m o l s} / \mathbf{g})$ & AChE $(\boldsymbol{\mu m o l s} / \mathbf{m i n} / \mathbf{m g})$ \\
\hline 1 & Normal (Vehicle) & $1.99 \pm 0.021$ & $0.24 \pm 0.018$ & $3.47 \pm 0.035$ & $7.12 \pm 0.140$ \\
2 & Sham (Surgery) & $1.65 \pm 0.025$ & $0.32 \pm 0.023$ & $3.27 \pm 0.030$ & $7.48 \pm 0.286$ \\
3 & Cerebral ischemia group & $1.43 \pm 0.021 \# \# \#$ & $0.48 \pm 0.047 \# \# \#$ & $0.85 \pm 0.039 \# \# \#$ & $10.52 \pm 0.244 \# \# \#$ \\
4 & GYM $(250 \mathrm{mg} / \mathrm{kg})$ & $1.80 \pm 0.139^{* *}$ & $0.36 \pm 0.013^{*}$ & $1.43 \pm 0.030^{* * *}$ & $9.28 \pm 0.475$ \\
5 & GYM $(500 \mathrm{mg} / \mathrm{kg})$ & $1.98 \pm 0.030^{* * *}$ & $0.31 \pm 0.010^{* * *}$ & $2.93 \pm 0.086^{* * *}$ & $8.44 \pm 0.404^{* *}$ \\
\hline
\end{tabular}

Values are expressed as (mean \pm S.E.M) Significant differences between Sham group and Ischemia group defined with \#, Significant differences between Surgery group and Treatment groups defined with *

\section{DISCUSSION}

Global cerebral ischemia in rat model used in this study resembles one of the heterogeneous groups of processes in ischemic stroke which is accounted for $85 \%$ of all strokes. Other category of strokes such as intracerebral bleeding (hemorrhagic stroke) accounts for the remainder (Beal et al., 2010). In the present study Gymnemic acid was evaluated for neuroprotective activity in bilateral common carotid artery occlusion induced global cerebral ischemia. In order to support neuroprotective property various biochemical parameters were evaluated. It has showed in literature that global cerebral ischemia produced of carotid artery occlusion and histopathological observations were made, the marked destruction of different lobes and cells of brain were seen (Oisson et al., 2003). The ischemic parts were confirmed by staining different regions of brain with hematoxylin and eosin stains.

Global cerebral ischemia model used in this study may be having various mechanisms such as energy failure, loss of cell ion homeostasis, acidosis, increased intracellular calcium levels, excitotoxicity, free radical-mediated toxicity, generation of arachidonic acid products, cytokine mediated cytotoxicity, complement activation, disruption of the blood-brain barrier (BBB), activation of glial cells, and infiltration of leukocytes. These are interrelated and coordinated events, which can lead to ischemic necrosis, which occurs in the severely affected ischemiccore regions. Within a few minutes of a cerebral ischemia, the core of brain tissue exposed to the most dramatic blood flow reduction, is mortally injured, and subsequently undergoes necrotic cell death. This necrotic core is surrounded by a zone of less severely affected tissue which is rendered functionally silent by reduced blood flow but remains metabolically active. Necrosis is morphologically characterized by initial cellular and organelle swelling, subsequent disruption of nuclear, organelle, and plasma membranes, disintegration of nuclear structure and cytoplasmic organelles with extrusion of cell contents into the extracellular space (Maino et al., 1995). Less severe ischemia, as occurs in the penumbra region of a focal ischemic infarct, evolves more slowly, and depends on the activation of specific genes and may ultimately result in apoptosis (Dirnagl et al., 1999; Lipton et al., 1999; Zheng et al., 2004). Increasing evidence suggests that oxidative stress and apoptosis are closely linked phenomena in the pathophysiology of ischemic stroke. Neurons are normally exposed to a baseline level of oxidative stress from both exogenous and endogenous sources, as are all cells in the body. Free radicals are highly reactive molecules with one or more unpaired electrons. Free radicals can react with DNA, proteins, and lipids, causing varying degrees of damage and dysfunction. Numerous experimental and clinical observations have shown increased free radical formation during all forms of stroke injury. Free radicals, involved in stroke induced brain injury, include superoxide anion radical, hydroxyl radical and nitric oxide (NO). The damaging effects of free radicals are normally prevented or reduced by antioxidant enzymes and free radical scavengers. The primary source of oxygen-derived free radicals (often referred to as 'reactive oxygen species') during ischemic-stroke injury is the mitochondria, which produce superoxide anion radicals during the electron transport process (Woodruff et al., 2011). During ischemia free radicals may be 
produced to such an extent that endogenous antioxidant systems are overwhelmed. Free radicals are demonstrated to promote lipid peroxidation. In the present study there was a significant increase in acetyl cholinesterase, lipid peroxidation levels and significant decrease in reduced glutathione, as well as total protein levels. Treatment with Gymnemic acid in doses of 250 and $500 \mathrm{mg} / \mathrm{kg}$ decreased acetyl cholinesterase, lipid peroxidation levels and increased in reduced glutathione as well as total protein levels. Histopathological observation supports the prevention in architecture of the brain due to the treatment with Gymnemic acid against occlusion induced cerebral ischemia in rat. Improvement in all antioxidant enzyme levels to significant values suggest antioxidant and free radical scavenger activity of Gymnemic acid against cerebral ischemia.

\section{CONCLUSION}

Cerebral ischemia produced neuronal damage is assessed by various histopathological and biochemical estimation mehods. Bilateral common carotid artery occlusion followed by treatment with Gymnemic acid in a dose of $250 \mathrm{mg} / \mathrm{kg}$ and $500 \mathrm{mg} / \mathrm{kg}$ b.w orally showed significant neuroprotective effect. Measured values of lipid peroxidase (LPO), reduced glutathione (GSH), Acetyl cholinesterase $(\mathrm{AChE})$, and total brain protein were showed a significant improvement in the levels compared to that of cerebral ischemia group. Hence, present findings indicate the possible exploitation of gymnemic acid for neuroprotective activity.

\section{Conflict of interest statement}

We declare that we have no conflict of interest.

\section{REFERENCES}

Beal CC. Gender and stroke symptoms, a review of the current literature. J Neurosci. Nurs, 2010;42:80-87.

Bhatiya AL, Kamal R, Verma G, Sharma KV, Vats S, and Jain M. Radio protective Role of Gymnemic Acid on Mice: Study on Hepatic Biochemical Alterations. Asian J Exp Sci, 2008;22(3):427-432.

Dalla Y, Singh N, Jaggi AS, Singh D, and Ghulati P. Potential of ezetimibe in memory deficits associated with dementia of Alzheimer's type in mice. Ind J Pharmcol, 2009;41(6):262-267.

Dateo GP, and Long L. Gymnemic acid, the antisaccharine principle of Gymnema sylvestre. Studies on isolation and heterogenesity of gymnemic acid $\mathrm{A}_{1}$. J Agri Food Chm, 1973;21:899-903.

Dirnagl U, Iadecola C, and Moskowitz MA. Pathobiology of ischaemic stroke an integrated view. Trends in Neuroscienc, 1999;22:391397.

Kiran N, and Kulkarni AR. Neuroprotective Effect of Acetogenin on Experimentally Induced Cerebral Ischemic Rats. World J Pharm Res, 2015;4(10):1757-1769.

Komalavalli N, Rao MV. In vitro micropropagation of Gymnema sylvestre: multipurpose medicinal plant. Plant Cell Tissue Organ Culture, 2000; 61: 97-105.
Lipton P. Ischemic cell death in brain neurons. Physiological Reviews, 1999;79:1431-1568.

Maeda M, Iwashita T, and Kurihara Y. Studies on taste modifiers II: Purification and structure determination of gymnemic acids, antisweet active principle from Gymnema sylvestre leaves. Tetrahedron Letters, 1989;30:1547-1550.

Majno G, Joris I. Apoptosis, oncosis, and necrosis - an overview of cell death. American J Patho, 1995;146:3-15.

Manni PE, Sinsheimer JE. Constituents from Gymnema sylvestre leaves. J Pharm Sci, 1965;54:1541-1544.

Masaya N, Masayuki N, Tomohiko I, Toshihiko U. Involvement of Free Radicals In Cerebral Vascular Reperfusion Injury Evaluated In a Transient Focal Cerebral Ischemia Model of Rat. Free Radical Biology \& Medicine, 1999;26(5,6):722-729.

Nakamura Y, Tsumura Y, Tonogai Y, Shibata T. Fecal steroid excretion is increased in rats by oral administration of gymnemic acids contained in Gymnema sylvestre leaves. J Nutr, 1999;129:1214-1222.

Olsson T, Wieloch T, Smith ML. Brain damage in a mouse model of global cerebral ischemia Effect of NMDA receptor blockade. Brain Research, 2003;982:260-269.

Porchezhian E, Dobriyal RM. An overview on the advances of Gymnema sylvestre" chemistry, pharmacology and patents. Pharmazie, 2013;58:5-12.

Satdive RK, Abhilash P, Fulzele DP. Antimicrobial activity of Gymnema sylvestre leaf extract. Fitoterapia, 2003;74:699-701.

Seshadri S, Beiser A, Hayes KM, Kase CS, Kannel WB, et.al. The life time risk of stroke - estimates from the Framingham study. Stroke, 2006;37:345-350.

Shigematsu N, Asano R, Shimosaka M, Okazaki M. Effect of administration with the extract of Gymnema sylvestre R.Br.V leaves on lipid metabolism in rats. Bio Pharm Bull, 2011;24:713-717.

Sinsheimer JE, Subbarao G. Constituents from Gymnema sylvestre leaves VIII: Isolation, chemistry and derivatives of gymnemagenin and gymnestrogenin. J Pharm Sci, 1971;60:191-193.

Tominaga M, Kimura M, Sugiyama K. Effect of Seishin-renshiin and Gymnema sylvestre on Insulin resistance in Streptozocin induced diabetic rats. Diabetes Res Clin Practice, 1995;29(1):11-17.

Wei-Ming Lin, Meng-Hsiang Chen, Hung-Chen Wang, et al. Association between Peripheral Oxidative Stress and White Matter Damage in Acute Traumatic Brain Injury. BioMed Res Int 2014, Article ID 340936, 8 pages, 2014. doi:10.1155/2014/340936

WHO Global Infobase: Proportional Mortality. WHO All Member States, 2004. Available from: URL: https://apps.who.int/infobase/Mortality.aspx.

Woodruff et. al., Pathophysiology, treatment, and animal and cellular models of human ischemic stroke. Molecular Neurodegeneration, 2011;6:11.

Yogisha S, Raveesha KA. In-vitro antibacterial effect of selected medicinal plant extracts. J Natural Product, 2009;2:64-69.

Yoshikawa K, Kondo Y, Arihara S, Matsuura K. Antisweet natural products IX structures of gymnemic acids XV-XVIII from Gymnema sylvestre R. Br. V. Chm Pharm Bull, 1993;41:1730-1732.

Zheng Z, Yenari MA. Post-ischemic inflammation: molecular mechanisms and therapeutic implications. Neuro Res, 2004;26:884-892.

\section{How to cite this article:}

Narkhede KP, Kulkarni AR, Savant C. Attenuation of Neuronal Damage by Gymnemic acid in Experimentally Induced Cerebral Ischemia in Rats. J App Pharm Sci, 2016; 6 (06): 113-118. 